\title{
Health Sector Evolution Plan in Iran; Equity and Sustainability Concerns
}

\author{
Maziar Moradi-Lakeh ${ }^{1,2^{*}}$, Abbas Vosoogh-Moghaddam ${ }^{3,4}$
}

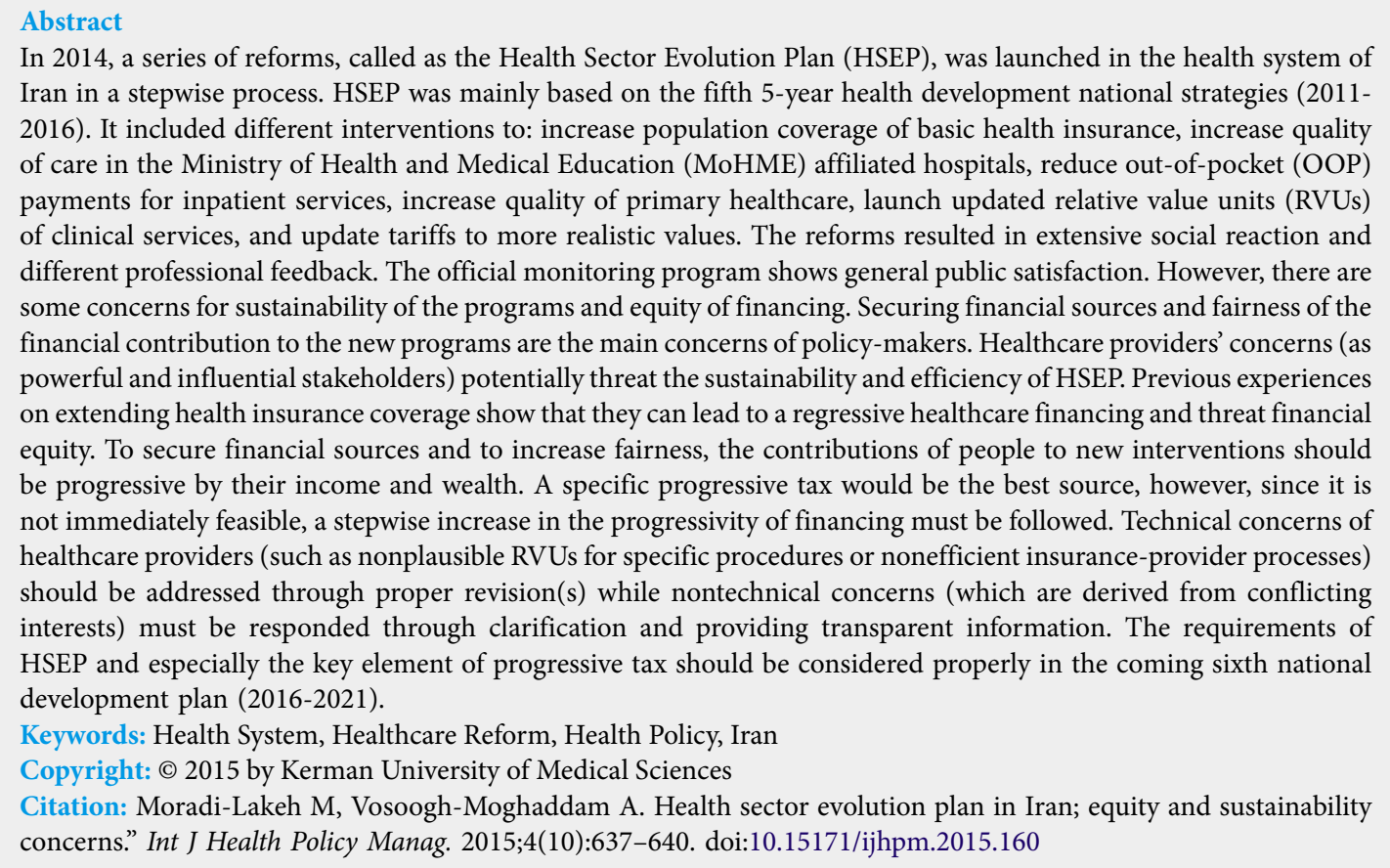

Article History:

Received: 22 May 2015

Accepted: 27 August 2015

ePublished: 31 August 2015

*Correspondence to:

Maziar Moradi-Lakeh Email: mmoradi@uw.edu

\section{Introduction}

The expansion of primary healthcare (PHC) in Iran in 1980s was mainly based on the principles of health for all as introduced in the conference of Alma-Ata. ${ }^{1}$ The PHC network considerably improved health outcomes, especially in rural areas, ${ }^{2}$ however, it was not adequate to meet emerging health needs of the population after a few decades. Also, expansion of services to urban and suburban areas and dynamics of patients' referral path were always challenging. ${ }^{3}$ Since 2005 , the family physician program, an updated referral path system and a reform package toward universal health insurance started in rural areas and small towns; they were later expanded by the following governments. ${ }^{4}$ In spite of some achievements in increasing population coverage of health insurance, there were still several known issues in access to healthcare and equity of financing and utilization. ${ }^{1,5-7}$ The 11 th government, elected in June 2013, launched series of reforms in 2014 to respond to some of the known issues in the performance of health system. The changes, so-called Health Sector Evolution Plan (HSEP) or Health Transformation Plan, were designed by the Ministry of Health and Medical Education (MoHME) based on the fifth 5-year health development national strategies (2011-2016) and the new President's manifest in order to achieve the universal and comprehensive health services coverage.

\section{What Is the Health Sector Evolution Plan?}

HSEP is a stepwise national plan which includes multiple interventions in the health sector, as summarized in this section. The following programs, are the main parts of the first phase of HSEP that were approved by the cabinet ${ }^{8}$ on April 30, 2014 to improve access to healthcare and quality of hospital care:

- Providing free basic health insurance to all Iranian uninsured individuals by Health Insurance Organization;

- Reducing out-of-pocket (OOP) payments for inpatient services at the hospitals affiliated with MoHME;

- Financial protection and support of patients with chronically disabling, or the so-called specific diseases [which include end-stage renal disease, thalassemia, hemophilia and multiple sclerosis], and those who are in need;

- Promotional policies to encourage medical doctors to stay in deprived areas;

- Improving quality of care in the hospitals affiliated with MoHME through different interventions such as 
increasing specialists, improving quality of outpatient services of the attached polyclinics and improving hospital amenities and lodging services;

- Compensation to offset the economic burden of the second phase of the targeted subsidies' law at hospitals affiliated with MoHME.

In addition to the above-mentioned programs, promotion of natural vaginal delivery and infertility treatments and improving the emergency medical services (eg, Medi-copter) were initiated as parts of the first phase, since May 5, 2014. The second phase of the HSEP (started on May 22, 2014) focused on the PHC and public health areas, included the following programs:

- Improving the family physician program and health insurance for nomadic people and residents of rural regions and small towns (population of less than 20000);

- Expanding health services to suburban areas;

- Improving the family physician program through a pilot project in 2 provinces (Fars and Mazandaran);

- Expanding the family physician program to cities with population of 20000-50000;

- Strengthening and institutionalizing inter-sectoral collaboration through the supreme council of health and food security;

- Increasing health literacy of people and enhancing selfcare.

Updated relative value units (RVUs) of health services was launched at the third phase of the HSEP (September 29, 2014) in order to regularize public and private service providers' payments based on the articles 32 and 38 of the fifth 5-year development plan. ${ }^{8-10}$

What Are the Financial Sources of Health Sector Evolution Plan?

The plan is mainly supported through the following financial sources: increased public annual budget of health sector (around 59\% increase in 2015 compared to the 2014), ${ }^{11}$ resources of the targeted subsidies' law (10\% of total subsidies) and a specific $1 \%$ value added tax (VAT) for health. The financial sources are estimated to be 70\% higher in 2015 (March 21, 2015-March 20, 2016) compared to 2014 (March 21, 2014-March 20, 2015). ${ }^{11,12}$ Based on the approved program, copayments for MoHME affiliated hospitals inpatient services must be limited to $10 \%$ for residents of the medium and large cities and 5\% for nomadic people and residents of rural regions, and small towns (with population less than 20000).

Why This Set of Programs Was Chosen?

Most of these reforms are based on the fifth 5-years national development plan $^{13}$ and aim to improve the following areas: notable percentage of uninsured individuals (around 17\% in 2010), ${ }^{14-16}$ inequitable health financing with a fair financing contribution index (FFCI) of 0.832 , OOP payments of more

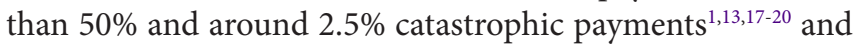
even more pessimistic estimates for FFCI and catastrophic payments in local studies. ${ }^{21,22}$ Also, there is evidence of the lack of sustainability of medical specialists in deprived areas, ${ }^{5}$ high rate of caesarian sections ${ }^{23,24}$ and high amounts of informal payments. ${ }^{25}$ Employer-sponsored health insurance systems in Iran were not able to equally protect people from catastrophic payments. ${ }^{19}$ On the other hand, previous interventions such as the Urban Inpatient Insurance Scheme (launched in 2000) and the Rural Health Insurance Scheme (launched in 2005) had regressive impacts on the distribution of healthcare financing in Iran. ${ }^{26,27}$

\section{Challenges and Potential Solutions}

The reforms resulted in extensive social reaction, especially in public and social media, and professional feedbacks. Based on the monitoring reports of the National Institute of Health Research, it seems that general population are satisfied with most of the HSEP components and the satisfaction has increased slightly during the first year of the program. ${ }^{28}$ Another study reported a lower satisfaction of patients in an academic hospital in Tehran after launch of HSEP which can be related to increased number of clients without a proper increase in the number of staff and other resources. ${ }^{29}$ Increasing coverage of basic health insurance and decreasing OOP payments are expected to increase access to healthcare, especially in underserved population, and decrease inequalities in healthcare utilization. ${ }^{23}$

It is too early to conclude, but at least during the first months after implementation, annual growth of consumer price index (CPI), from March 2014 to March 2015, for health services is still higher than CPI for all items (33.2\% vs. $16.2 \%$ ), somewhat similar to CPI growth rates from March 2013 to March 2014. which means that share of health from total consumers' market basket has not been decreased. ${ }^{30}$ This might be due to the fact that a relatively small percentage of the population need inpatient services during a year and the most important components of OOP payments are medications/equipment and outpatient services (around $40 \%$ and 34\%, respectively). ${ }^{31}$ However, the program is expected to be more successful in decreasing catastrophic payments, because inpatient service utilization is the most important factor associated with facing catastrophic health expenditures in Iran. ${ }^{32}$

To increase fairness, the financial contributions of people for new interventions should be progressively correlated with their income and wealth. This could lead to a positive or pro-poor redistributive effect and can be achieved through different interventions such as a designated progressive $\operatorname{tax}^{33}$ On the other hand, such tax-based sources increase sustainability of the reform programs. Financial sources linked to a progressive tax is a key indicator both for fairness and sustainability of the program..$^{34,35}$ This is not an easy to achieve goal because of the high rate of tax evasion and size of the underground economy in Iran, ${ }^{36}$ however, policy-makers and managers should define specific objectives to gradually replace current sources of HSEP by other sources that are progressive. Current combination of rules and regulations for direct and indirect taxation in Iran, provides a basic infrastructure for this transition and economic situation of the country (during the international economic sanctions period) has changed attitudes in favor of progressive taxation. Ignoring this key element in the previous interventions such as the Urban Inpatient Insurance Scheme and the Rural Health Insurance Scheme led to regressive impact on healthcare financing. ${ }^{27}$ On the other hand, HSEP changes raised concerns about the economic burden of the program on the public budget and sustainability of the program in the 
following years. ${ }^{12}$ Some experts believe that MoHME should focus and invest on $\mathrm{PHC}$ and preventive programs (which are more efficient for increasing population health) instead of spending most of the new financial sources on therapeutic and hospital services. ${ }^{37}$

As expected, introduction of new approved RVUs of the individual health services, ${ }^{10}$ at the third phase of HSEP, were among the most challenging parts of the reforms program; it was accompanied by an official increase in the national tariff units toward more realistic amounts and a concurrent rigorous control over informal payments to the providers. These changes led to a generally higher satisfaction in medical specialists who work in the governmental hospitals compared to the other healthcare personnel and other hospitals. ${ }^{28}$ There are several groups of healthcare professionals who are somehow disappointed: some of the medical specialists have technical concerns about RVUs of specific procedures and services in their field of work and claim that they are not properly related to level of expertise, stress, time and effort of practitioners ${ }^{38}$; however, it is hard to differentiate real technical concerns from conflicting interests. A group of medical specialists are dissatisfied with new RVUs and tariffs, because they are not enough to compensate their income loss after increasing control over informal transactions. Since this reason cannot be stated frankly, they exaggerate other shortcomings and try to stop or revert this part of the program. Other healthcare providers, such as registered nurses and general practitioners (nonspecialist medical doctors), feel and claim that recent changes have unfairly widened the income gap between specialist doctors and other healthcare providers. ${ }^{39}$ Moreover, a combination of decreased OOP payments and increasing quality of care in hospitals affiliated with MoHME (as claimed) might indirectly affect private hospitals which have already been impacted by increased control over the informal transactions. These are all powerful opponents that could influence sustainability of the plan. Policy analysis, even at this phase, can help the designers to find less painful strategies for the decision-makers to establish and continue reforms. Real technical concerns must be responded to properly, and fixing technical issues is necessary to establish reforms smoothly.

We conclude that a stepwise increase in progressive financing is a key factor both for equity of financing and sustainability of HSEP. Real technical concerns of stakeholders should be addressed through proper and efficient revision(s) such as redefining and improving insurance-provider transaction process. Nontechnical statements which have roots in conflicting interests should be detected and responded by clarification and providing transparent information. Strict monitoring of the reform process, evaluating the results and transferring of findings to the stakeholders and general public are necessary. An accurate policy analysis for the continuation of the program components and new revisions/interventions can facilitate the process. All the requirements of the HSEP continuation should be considered properly in the coming sixth national development plan (2016-2021) in line with the country general policies on health.

Ethical issues

Not applicable.
Acknowledgments

Authors would like to thank Beth King for editing the manuscript.

Competing interests

Authors declare that they have no competing interests.

\section{Authors contributions}

MML and AVM contributed to the conception of the work, collection and interpretation of the related information. MML prepared the draft of manuscript. AVM commented on the draft. Both authors verified the final version.

\section{Authors' affiliations}

${ }^{1}$ Institute for Health Metrics and Evaluation, University of Washington, Seattle, WA, USA. 'Department of Community Medicine, Iran University of Medical Sciences and Health Services, Tehran, Iran. ${ }^{3}$ Health Sector Policy Coordination Group, in Charge of Minister for Policy Making Affairs Bureau, Ministry of Health and Medical Education, Tehran, Iran. ${ }^{4}$ NCD Research Center, Endocrine and Metabolism Research Institute, Tehran University of Medical Sciences and Health Services, Tehran, Iran.

\section{References}

1. Manenti A. Health situation in Iran. Med J Islam Repub Iran. 2011;25(1):1-7.

2. Shadpour K. Primary health care networks in the Islamic Republic of Iran. East Mediterr Health J. 2000;6(4):822-825.

3. Takian A, Rashidian A, Kabir MJ. Expediency and coincidence in re-engineering a health system: an interpretive approach to formation of family medicine in Iran. Health Policy Plan. 2011;26(2):163-173. doi:10.1093/heapol/czq036

4. Takian A, Doshmangir L, Rashidian A. Implementing family physician programme in rural Iran: exploring the role of an existing primary health care network. Fam Pract. 2013;30(5):551559. doi:10.1093/fampra/cmt025

5. Lankarani KB, Alavian SM, Peymani P. Health in the Islamic Republic of Iran, challenges and progresses. Med J Islam Repub Iran. 2013;27(1):42-49.

6. Moradi-Lakeh M, Bijari B, Namiranian N, Olyaeemanesh A-R, Khosravi A. Geographical disparities in child mortality in the rural areas of Iran: 16-years trend. J Epidemiol Community Health. 2013;67(4):346-349. doi:10.1136/jech-2012-201511

7. Zare H, Trujillo AJ, Driessen J, Ghasemi M, Gallego G. Health inequalities and development plans in Iran; an analysis of the past three decades (1984-2010). Int J Equity Health. 2014;13:42. doi:10.1186/1475-9276-13-42

8. Cabinetapproval. http://www.behdasht.gov.ir/uploads/1_187198. pdf. Accessed May 10, 2015. Published April 2014.

9. Cabinet approval. Relative values of health services and tariffs. http://rvu. behdasht.gov.ir/index.aspx?fkeyid=\&siteid=431\&pagei $d=54134$ \&newsview=119678. Accessed May 10, 2015.

10. Ministry of Health and Medical Education (MoHME). Health Sector Evolution Portal. http://tahavol.behdasht.gov.ir/index.asp x? fkeyid=\&siteid=426\&pageid=52443. Accessed May 18, 2015.

11. Islamic Parliament Research Center (IPRC). Assessment of national annual budget proposal of 1394. 26- Health sector. 2014. http://rc.majlis.ir/fa/report/show/916417. Accessed August 21, 2015.

12. Mare Sedgh S. A growth in health budget by $70 \%$. http://www. shefanews.com/fa/news/33033. Accessed August 16, 2015. Published December 2014.

13. Vosoogh Moghaddam A, Damari B, Alikhani S, et al. Health in the 5th 5-years Development Plan of Iran: Main Challenges, General Policies and Strategies. Iran $J$ Public Health. 2013;42(Supple1):42-49.

14. Iran National Institute of Health Research. Universal Health 
Coverage in Iran. Vol First. Tehran, Iran: Gozineh Parsian Teb; 2015. http://nihr.tums.ac.ir/wp-content/uploads/2015/08/uhcbook-edit1.pdf. Accessed August 8, 2015.

15. Davari M, Haycox A, Walley T. The Iranian Health Insurance System; Past Experiences, Present Challenges And Future Strategies. Iran J Public Health. 2012;41(9):1-9.

16. Rashidian A, Khosravi A, Khabiri R, et al. Islamic Republic of Iran's Multiple Indicator Demograpphic and Healh Survey (IrMIDHS) 2010. Tehran: Ministry of Health and Medical Education, 2012. http://nihr.tums.ac.ir/Images/Archive/fffe97ff-53a0-486a-871d3a10d48f6a6b.pdf. Accessed May 11, 2015.

17. Abolhallaje M, Hasani S, Bastani P, Ramezanian M, Kazemian M. Determinants of Catastrophic Health Expenditure in Iran. Iran J Public Health. 2013;42(Supple1):155-160.

18. Fazaeli AA, Seyedin $H$, Moghaddam AV, et al. Fairness of Financial Contribution in Iranian Health System: Trend Analysis of National Household Income and Expenditure, 2003-2010. Glob J Health Sci. 2015;7(5):260.

19. Hajizadeh M, Nghiem HS. Out-of-pocket expenditures for hospital care in Iran: who is at risk of incurring catastrophic payments? Int J Health Care Finance Econ. 2011;11(4):267-285.

20. Statistical center of Iran. Iran National Health Accounts, 20022008. https://www.amar.org.ir/Portals/0/topics/sna/hesab_ salamat.pdf. Accessed August 21, 2015. Published 2011.

21. Kavosi Z, Keshtkaran A, Hayati R, Ravangard R, Khammarnia $M$. Household financial contribution to the health System in Shiraz, Iran in 2012. Int J Health Policy Manag. 2014;3(5):243249. doi:10.15171/ijhpm.2014.87

22. Daneshkohan A, Karami M, Najafi F, Matin BK. Household catastrophic health expenditure. Iran $J$ Public Health. 2011;40(1):94-99.

23. Iran National Institute of Health Research. Monitoring of Health Sector Evolution Plan, Report 1. http://nihr.tums.ac.ir/wpcontent/uploads/2015/04/file3.pdf. Accessed August 8, 2015. Published September 2014.

24. Moradi-Lakeh M, Ramezani M, Naghavi M. Equality in safe delivery and its determinants in Iran. Arch Iran Med. 2007;10(4):446-451.

25. Nekoeimoghadam M, Esfandiari A, Ramezani F, Amiresmaili M. Informal payments in healthcare: a case study of Kerman province in Iran. Int J Health Policy Manag. 2013;1(2):157-162. doi:10.15171/ijhpm.2013.28

26. Hajizadeh M, Connelly LB. Equity of health care financing in Iran. http://mpra.ub.uni-muenchen.de/14672. Accessed August 21, 2015. Published 2009.

27. Hajizadeh M, Connelly LB. Equity of health care financing in
Iran: the effect of extending health insurance to the uninsured. Oxf Dev Stud. 2010;38(4):461-476.

28. Iran National Institute of Health Research. Monitoring of Health Sector Evolution Plan, Reports 3. http://nihr.tums.ac.ir/wpcontent/uploads/2015/04/Satisfaction-3.pdf. Accessed August 8, 2015. Published winter 2015.

29. Hashemi B, Baratloo A, Forouzafar MM, Motamedi M, Tarkhorani M. Patient Satisfaction Before and After Executing Health Sector Evolution Plan. Iran J Emerg Med. 2015;2(3).

30. Central Bank of the Islamic Republic of Iran, General Directorate of Economic Statistics. Consumer Price Index for All Urban Consumers - Esfand 1393 (February 20 - March 20, 2015) $(1390=100)$. http://www.cbi.ir/category/1611.aspx. Accessed May 10, 2015. Published April 2015.

31. Lankarani KB, Ghahramani S, Zakeri M, Joulaei H. Lessons learned from national health accounts in Iran: highlighted evidence for policymakers. Shiraz E-Medical Journal. 2015;16(4):e27868.

32. Kavosi Z, Rashidian A, Pourreza A, et al. Inequality in household catastrophic health care expenditure in a low-income society of Iran. Health Policy Plan. 2012;27(7):613-623. doi:10.1093/ heapol/czs001

33. Wagstaff A. Reflections on and alternatives to WHO's fairness of financial contribution index. Health Econ. 2002;11(2):103-115.

34. Reeves A, Gourtsoyannis Y, Basu S, McCoy D, McKee M, Stuckler D. Financing universal health coverage--effects of alternative tax structures on public health systems: cross-national modelling in 89 low-income and middle-income countries. Lancet Lond Engl. 2015;386(9990):274-280. doi:10.1016/S0140-6736(15)60574-8

35. Yates R. Universal health coverage: progressive taxes are key. Lancet Lond Engl. 2015;386(9990):227-229. doi:10.1016/ S0140-6736(15)60868-6

36. Karimi Petanlar S, Gilak MT, Samimi AJ, Aminkhaki A. An Estimation of Tax Evasion in Iran. J Econ Behav Stud. 2011;3(1):8-12.

37. Forghani A. Cash on the Health Sector Evolution Plan. Alef Post Code 271691. http://alef.ir/vdcdnf0xfyt0596.2a2y.html?271691. Accessed August 15, 2015. Published May 2015.

38. Fazel I. Letter of the President of the Iranian Association of Surgeons (Dr. Iraj Fazel) to the Minister of Health. http://nemc. ir/news.php?extend.746. Accessed August 21, 2015. Published November 2014.

39. Health sector evolution plan and increasing objections of the nurses community. http://www.ilna.ir/. Accessed August 21, 2015. 